\title{
Creating Better Online Solutions For Healthcare Providers With KM: The Case Of Allergy Care
}

\author{
Nilmini Wickramasinghe \\ Epworth HealthCare \& Deakin University, Australia \\ nilmini.work@gmail.com
}

\begin{abstract}
Today, in healthcare many online solutions are being designed and developed; however many of these fall short of delivering a superior care experience. The following investigates the benefits of incorporating a knowledge management (KM) perspective when designing and developing online solutions. Specifically, the paper focusses on the design and development of an online solution in the context of paediatric allergies, their initial diagnosis and ongoing follow up monitoring and management. The solution is guided by KM principles, and comprises a central knowledge base for allergy patients. This knowledge base is designed to be accessed by both healthcare providers and patients and their families to save reviewing time and enhance the flow of germane medical information/knowledge among allergy care providers.
\end{abstract}

\section{Introduction}

The numbers of patients suffering from allergy are globally increasing [1]. Recent data generated from the local Healthnuts study has identified an increase of $20 \%$ sensitisation and a $10 \%$ challenge confirmed food allergy rate in 12 month old Melbourne infants [24][25][26], the picture of allergy in Australia in general looks even more worrying [2]. According to a report made for the Australasian Society of Clinical Immunology and Allergy (ASCIA) in 2007 [3], there were 4.1 million Australians (19.6\%) having at least one allergy, and the average Australian allergic person with 1.74 allergies, forecasting of $70 \%$ in the number of Australians with allergies affected from 4.1 million now to 7.7 million by 2050 , and an increased proportion affected from $19.6 \%$ to $26.1 \%$ if the trends back then continued [3][13] (Access Economics Pty Limited, 2007).

The financial impact of allergy treatment is significant and growing; 7.8 billion Australian dollars was the calculated cost of allergies in Australia in 2007 and this number is projected to increase exponentially in the next 20 years [13]. This is due to different interrelated factors like lower productivity ("presenteeism" $\$ 4.2$ billion), direct medical costs ( $\$ 1.2$ billion), lower employment rates (\$1.1 billion), absenteeism and lost household productivity ( $\$ 0.2$ billion) and premature death (\$83 million)[3]. Hence, focussing on identifying superior cost effective solutions to support allergy care as this study sets out to do, is a key need in the Australian healthcare environment.

\section{Background}

Food allergy diagnosis is confirmed by a positive allergy test (Skin Prick Test [SPT] or serum specific IgE [ssIgE] blood test) in conjunction with a history of an immediate allergic reaction to that food [24][26][28]. However, screening allergy testing is frequently performed in the community prior to a patient having known exposure to a food allergen, particularly in at risk patient groups eg. patients' with Atopic Dermatitis (AD) [ibid]. The size of the SPT or level of ssIgE are used as guides as to the likelihood or otherwise of clinical food allergy [15].

The gold standard for food allergy diagnosis in this setting is by a physician supervised food challenge [24][26][28]. Most food allergies in childhood resolve over time (eg. egg, milk, wheat, soy); however, allergies to peanut, tree nut, fish and shellfish tend to be ongoing into adult life in up to $80-90 \%$ of patients [24][26][28]. To follow up for the development of potential clinical tolerance patients are re-evaluated every few years with repeat allergy testing (either SPT or ssIgE) [28]. The size of the SPT or level of SsIgE are used as guides as to the likelihood or otherwise of the development of clinical tolerance [24][26]. Serial allergy testing over several years is common before the allergy test (SPT or ssIgE) is at a level where it may be considered appropriate to proceed with an oral food challenge (figure 1) [30].

It is not an unusual clinical practice for clinicians to provide patients with a copy of their SPT results each time the test is performed as well as keep a record of the test in either written or electronic form in their patient database [24][26][28]. As allergy services are currently stretched, there are frequently prolonged waiting 
times for food allergy review, particularly in the public sector [13]. Further, it is often the case for patients to be seen by different Allergy practitioners for follow up testing in the longer term [13]. In the interim patients are frequently encouraged to visit their general practitioner for food allergy follow up that may include intermittent evaluation of yearly or second yearly ssIgE to the food allergen(s) in question [13]. In the event that these levels are low or approaching negative, re-referral for follow up and consideration of formal inpatient challenge may be appropriate [13]. In this situation, it is common that previous test results are not readily available for comparison [11]. Especially given that there is some evidence to suggest that the rate of change in SPT size or ssIgE levels over time may help in predicting the development of tolerance, this is clearly a suboptimal scenario [24][26][28].

Providing allergy care thus, seems to lack accurate and reliable data within and between different allergy care providers. According to HoChang, Chang, and Prybutok [16], more than 57\% of 89 countries around the world had no food allergy prevalence data of any kind, and just $10 \%$ of these countries had this sort of data. Hence, analysing the current approaches to treat allergy [29] and then designing and developing a technology solution to support and enable high value superior care in this domain appears to be a prudent approach. It would appear that the main deficiencies relate to the lack of documenting serial allergy test results (both SPT size and ssIgE levels) over time in a readily available and consistent dataset by both allergists and their patients. So offering this possibility would be an invaluable tool in the long term management of these patients. Thus, this study aims to develop an online solution for use by both allergists and their patients to ensure prospective accurate and secure collection of SPT and ssIgE data for long term follow-up of patients with food allergy.

This study is conducted in conjunction with an Australian private healthcare provider. Within this hospital, there is an allergy clinic was established in 2010 to provide a comprehensive service for children, adolescents and adults with allergic and immune disorders including the long term follow up and management of patients with food allergy. This clinic is the first such service to provide safe inpatient food challenges in the private sector in Australia. To date, this clinic has performed over 2000 food challenges to confirm or refute the development of tolerance to previously identified food allergens with a positive challenge rate of $20 \%$. These challenges are not without risk with anaphylaxis occurring in $2 \%$ of all challenges currently performed at the study site, highlighting the importance of a service with expert staff equipped to deal with potentially life threatening anaphylaxis [16][18].

\section{Knowledge Management}

Knowledge Management (KM) is a multidisciplinary paradigm that is aimed at solving the business challenges to increase efficiency and efficacy of core business processes while simultaneously incorporating continuous innovation and enabling superior decision making [10][4]. Specifically, KM through the use of various tools, processes and techniques combines germane organizational data, information and knowledge to create value and enable an organization to capitalize on its intangible and human assets so that it can effectively achieve its primary business goals as well as maximize its core business competencies [4][8][9][20][32][33][34].

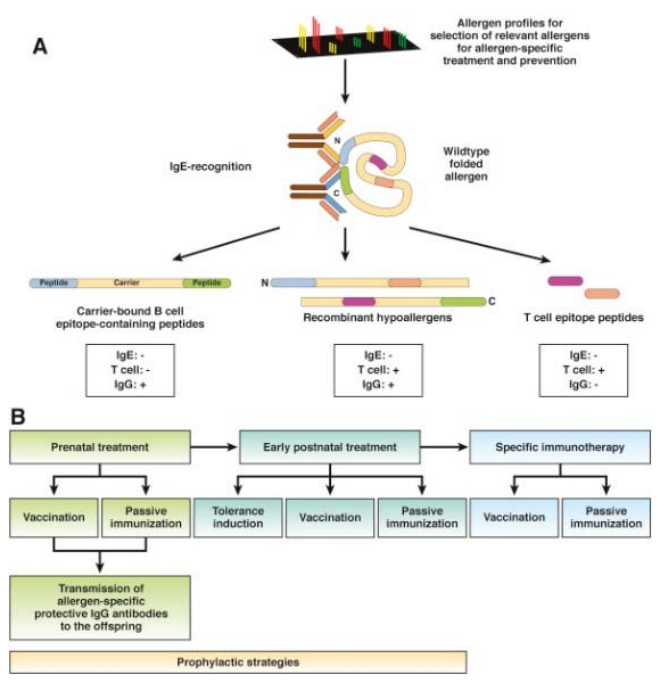

Figure 1 Key aspects in allergy management [26]

The premise for the need for KM is based on a paradigm shift in the business environment where knowledge is central to organizational performance [4][8][9][10][20][32][33][34].

Knowledge management deals with distinct, but related, concepts, starting from data (raw knowledge), to information (data arranged into a meaningful pattern, to knowledge (contextualised information, and wisdom, upon its existence beyond knowledge there is a wide agreement [32][33]. Central to KM is naturally the knowledge construct. Knowledge is not static; rather it changes and evolves during the life of an organization [4][10]. What is more, it is possible to change the form of knowledge; i.e., turn existing tacit knowledge (or experiential "know how") into new explicit knowledge (or factual "know what") and existing explicit knowledge into new tacit knowledge $[21][22][23][32]$. This process of changing the form of knowledge is known as the knowledge spiral [32][33][34], in which, according to Nonaka [21][22][23]: 1) Tacit to tacit knowledge transfer usually occurs through apprenticeship type relations 
where the teacher or master passes on the skill to the apprentice. 2) Explicit to explicit knowledge transfer usually occurs via formal learning of facts. 3) Tacit to explicit knowledge transfer usually occurs when there is an articulation of nuances; for example, if a famous surgeon is questioned as to why he does a particular procedure in a certain manner, by his articulation of the steps the tacit knowledge becomes explicit. and 4) Explicit to tacit knowledge transfer usually occurs as new explicit knowledge is internalized it can then be used to broaden, reframe and extend one's tacit knowledge.

These transformations are often referred to as the modes of socialization, externalization, internalization and combination respectively [21][22][23]. Integral to this changing of knowledge through the knowledge spiral is that new knowledge is created [32[33][34] and this can bring many benefits to organizations. In the case of transferring tacit knowledge to explicit knowledge for example, an organization is able to capture the expertise of particular individuals; hence, this adds not only to the organizational memory but also enables single loop and double loop organizational learning to take place [33]. In healthcare, this may translate, for example, to the developing of better protocols and codes or even further refinement to existing DRGs (Diagnosis Related Groupings). While the transformations of the knowledge spiral provide a theoretical framework (that facilitates the understanding of the complex knowledge), in order to be useful in practice (i.e. for our purposes), these transformations must occur and/or be invoked to assist in the superior diagnosis and consequent prognosis and treatment of paediatric allergies.

\subsection{Knowledge Management for Healthcare}

With the ever increasing volume of data being produced daily in the electronic medical records (EMR) and clinical databases, knowledge management approaches provide a tools-rich platform to perform pattern-identification tasks, such as detecting associations between certain risk factors and outcomes, ascertaining trends in healthcare utilisation, or discovering new models of disease in populations, the tools and techniques of KM are very relevant to healthcare and this particular context; allergy detection, prediction and on-going treatment management [34].

In their comprehensive assessment of applying knowledge management in the healthcare industry, Wickramasinghe et al.[35] noted that the gap between data collection and data comprehension and analysis is becoming more problematic, given the increased volume and complexity of clinical data, which, in one way or other, reflects the complexity of the healthcare itself and thus the tools of KM are applied to this research.

\subsection{The Application of Knowledge Management on this Study}

The tools, tactics, and techniques of $\mathrm{KM}$ are relevant as follows: First, the designed data base to store results and tests is expected to produce high volumes of data on different types of allergy in different age groups. Not only is the volume demanding, but also the complexity of the produced data is an issue. Those two factors combined, make the use of know management prudent to maximise the benefit of using the designed knowledge base. Second, KM techniques will help bridge the gap between data collection as a routine procedure and data comprehension and analysis as an innovative and iterative process. This is important based on the aforementioned explanation. Third, it will help clinicians to better understand their patient data with less effort and time; i.e., they can focus on pertinent information and germane knowledge, which, in turn, increases the efficiency and efficacy of their daily business. Fourth, the aim of this study is to create reliable and exchangeable knowledge among different allergy treatment providers, rather than merely creating the knowledge base. This is a central aspect of any knowledge management approach, by moving from raw knowledge (data), which is much context-dependent, to knowledge and then ideally wisdom, which are much more context-independent (Nonaka).

\section{The Proffered Solution}

An essential aspect of the proffered solution is an electronic knowledge base which will ensure prospective accurate collection of allergy test results over time. In doing so, this will enable ready access to these results by both patients and clinicians at each point of contact with health service providers to aide in the long term follow-up and management of these patients with food allergies. The knowledge base will be designed to alert patients to appropriate timing for re-evaluation and potential consideration for food challenge; thereby, allowing timelier introduction of food to which they had previously reacted or had allergy test results predictive of likely true clinical allergy.

The longer term plan is to develop the knowledge base into a usable application for smartphone/ hand held devices increasing portability/usability and autonomy of patient groups with allergic disease so that access to critical and potentially lifesaving information is readily available at their fingertips in real time.

\section{Study Design Methodology}

This study adopts a single case study [36] and Design Science Research Methodology (DSRM) 
[27]). Case study research is appropriate when a study is exploratory in nature and it is desired to capture the knowledge of practitioners and developing theories from it [7]. Further, as a main focus of this study is to design an online solution that facilitates knowledge transfer and sharing among different allergy care providers a DSRM approach is also adopted (figure2a and 2b) [27]. DSRM is a process model that helps carry out research focussed on designing artefacts [14]. This methodology is widely used quantitatively to improve existing solutions, or qualitatively to create new solutions to unsolved problems [12]. In this research, this methodology is used qualitatively given the nature of this study as it aims at creating a novel solution for an existing problem [31]; namely, the fragmented chain of knowledge sharing among allergy care providers. Hevner [27], conceptualises DSRM in three cycles, including: Relevance Cycle, Rigor Cycle, and Design Cycle. According to this framing, DSRM starts with the relevance cycle whose role is centred on providing the requirements for the research by identifying the opportunity/ problem to be addressed [27]. The rigor cycle is centred on providing past knowledge to the research project to ensure its innovation while the design cycle concentrates on building the artefacts and processes, and evaluating them [27]. As this research is in its initial stages, the relevance and design cycles are relevant to this study at this stage. Upon the building of the solution, the rigor cycle will then be addressed. Table 1 summarises how the relevance and design cycles are mapped to this study.

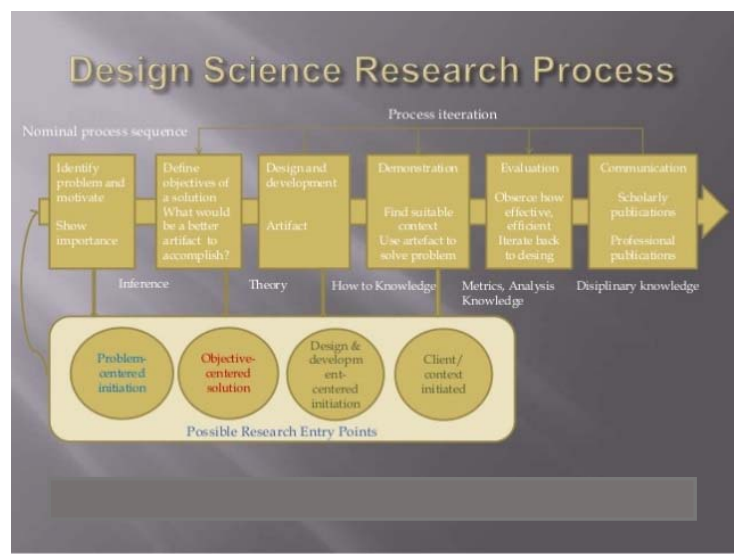

Figure 2a DSRM (adapted from [27])
- $\quad$ Storyboarding with head of clinic to clearly understand needs and requirements.

- Investigating the possibility to securely store photos of results of skin prick tests with data.

- Creating an App that the clinicians can use to enter skin prick test data.

- Creating a secure encrypted knowledge base.

- $\quad$ Ensuring data is backed up automatically.

- Calculating the "mean" for each allergen.

- Generating a trend analysis for each patient.

- Creating a printout results to replicate the existing Skin Prick Test.

- $\quad$ Printing out an informative results sheet for parents/patients.

- $\quad$ Testing and validation of the product.

- Testing the fidelity and validity of the knowledge base.

The testing will be done over a 3 month period through a two-arm non-blinded study, during which patients who agree to participate will be randomly selected into the technology arm (knowledge base plus standard care protocols) or standard care arm (current practice method) respectively. Clinicians will then perform the required allergy testing and consult using respectively the technology solution or standard care approach. We note that for the technology arm the research assistant will still complete the paper work as directed by the clinician so at all times all patients will at a minimum receive the same standard care.

On the completion of the trial a focus group with the clinicians will be conducted to capture their insights on the usability of the proposed system, as well as their comments, recommendations and other feedback. Fidelity of the system will also be assessed by comparing standard care results with the technology arm results. To ensure the validity of the data collected through the focus group, an online survey will be administered at the conclusion of the focus group to ensure data triangulation.

This study has two distinct phases:

1) Designing the technology solution; the knowledge base,

2) Testing the fidelity and usability of the designed knowledge base. Key activities include: 


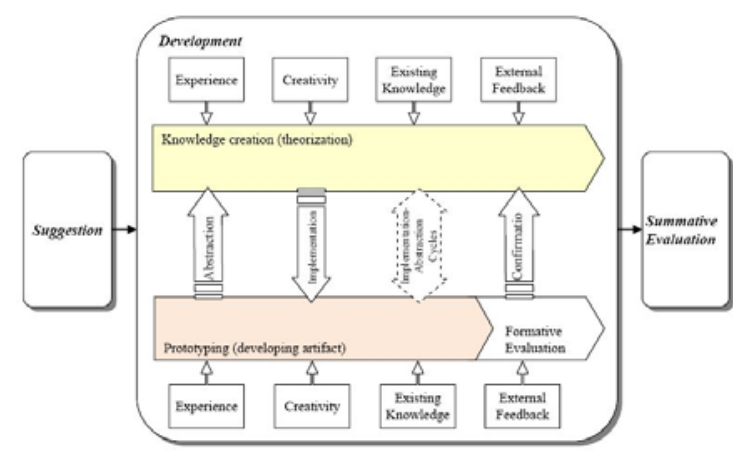

Figure 2b DSRM for prototyping (adapted from [27])

\begin{tabular}{|c|c|c|}
\hline $\begin{array}{l}\text { DSRM } \\
\text { Activity }\end{array}$ & $\begin{array}{c}\text { Activity } \\
\text { Description }\end{array}$ & $\begin{array}{l}\text { Application } \\
\text { on this study }\end{array}$ \\
\hline $\begin{array}{l}\text { Problem } \\
\text { identificati } \\
\text { on and } \\
\text { motivation }\end{array}$ & $\begin{array}{l}\text { Define the } \\
\text { specific } \\
\text { research } \\
\text { problem and } \\
\text { justify the } \\
\text { value of a } \\
\text { solution. }\end{array}$ & $\begin{array}{l}\text { Increasing rates of food } \\
\text { allergy diagnosis, the } \\
\text { lack of a computerised } \\
\text { information and } \\
\text { communication system } \\
\text { to support knowledge } \\
\text { flow among allergy care } \\
\text { and the need to address } \\
\text { this gap. }\end{array}$ \\
\hline $\begin{array}{l}\text { Definition } \\
\text { of } \\
\text { objectives } \\
\text { of the } \\
\text { solution }\end{array}$ & $\begin{array}{l}\text { Create or } \\
\text { improve an } \\
\text { artefact } \\
\text { respectively } \\
\text { based on } \\
\text { knowledge of } \\
\text { the problem } \\
\text { and current } \\
\text { solutions, if } \\
\text { any, and their } \\
\text { efficacy. }\end{array}$ & $\begin{array}{l}\text { The objective is to create } \\
\text { an artefact to address the } \\
\text { fragmented nature of } \\
\text { allergy care. }\end{array}$ \\
\hline $\begin{array}{l}\text { Design } \\
\text { and } \\
\text { developme } \\
\text { nt }\end{array}$ & $\begin{array}{l}\text { Create the } \\
\text { artefact, } \\
\text { including the } \\
\text { desired } \\
\text { functionality } \\
\text { and its } \\
\text { architecture } \\
\text { based of } \\
\text { knowledge of } \\
\text { theory that } \\
\text { can be used to } \\
\text { bear in a } \\
\text { solution. }\end{array}$ & $\begin{array}{l}\text { The artefact is to be } \\
\text { designed to facilitate } \\
\text { knowledge sharing and } \\
\text { flow among different } \\
\text { allergy care providers To } \\
\text { do so, the design phase is } \\
\text { conducted } \\
\text { collaboratively between } \\
\text { the researchers and the } \\
\text { clinicians at the selected } \\
\text { case. }\end{array}$ \\
\hline $\begin{array}{l}\text { Demonstrat } \\
\text { ion }\end{array}$ & $\begin{array}{l}\text { Demonstrate } \\
\text { the use of the } \\
\text { artefact to } \\
\text { solve the } \\
\text { problem. }\end{array}$ & $\begin{array}{l}\text { The artefact is to be } \\
\text { tested and tried, and then } \\
\text { in-depth analysis will be } \\
\text { performed to measure } \\
\text { the extent to which the } \\
\text { proposed system helps } \\
\text { solve the problem. }\end{array}$ \\
\hline Evaluation & $\begin{array}{l}\text { Iterate back to } \\
\text { better design } \\
\text { the artefact if } \\
\text { needed. }\end{array}$ & $\begin{array}{l}\text { As needed, iteration back } \\
\text { will take place, based on } \\
\text { in-depth analyses to } \\
\text { identify rooms of } \\
\text { improvement }\end{array}$ \\
\hline $\begin{array}{l}\text { Communic } \\
\text { ation }\end{array}$ & $\begin{array}{l}\text { Publish and } \\
\text { let the value } \\
\text { of the } \\
\text { solution talk } \\
\text { about itself. }\end{array}$ & $\begin{array}{l}\text { Conference and journal } \\
\text { publications and other } \\
\text { presentation activities to } \\
\text { develop the project } \\
\text { further and share the } \\
\text { findings with interested } \\
\text { stakeholders. }\end{array}$ \\
\hline
\end{tabular}

Table 1. Mapping DSRM [27] to the proposed system

\subsection{Setting and Participants}

As stated by Hung and Cheng [17], individual's positive attitude, such as optimism, toward the Technology Readiness Index, positively affects acceptance of technology; an individual's negative perception of the Technology Readiness Index, such as discomfort, has a negative effect on 
his or her sense of the perceived ease of technology and compatibility in regard to prior experience and technology. Thus, during the research design phase, addressing the technological concerns of the allergy

\begin{tabular}{|l|l|c|}
\hline $\begin{array}{c}\text { Key } \\
\text { Participan } \\
\text { ts/Key } \\
\text { Milestones }\end{array}$ & Participants/Records & $\begin{array}{c}\text { participant } \\
\text { numbers }\end{array}$ \\
\hline $\begin{array}{l}\text { Initial } \\
\text { Discussions }\end{array}$ & $\begin{array}{l}\text { Specialist doctor } \\
\text { (allergist) }\end{array}$ & $\bullet$ \\
\hline $\begin{array}{l}\text { Patients' } \\
\text { records }\end{array}$ & $\begin{array}{l}\text { De-identified Patients' } \\
\text { records (historical } \\
\text { records) randomly } \\
\text { selected. }\end{array}$ & $\begin{array}{l}\text { Patient } \\
\mathrm{s}^{\prime} \\
\text { record } \\
\mathrm{s}:<= \\
50 \\
\text { record } \\
\mathrm{s}\end{array}$ \\
\hline $\begin{array}{l}\text { Focus } \\
\text { Group }\end{array}$ & $\begin{array}{l}\text { Clinicians work in } \\
\text { allergy care. } \\
\text { This will be conducted } \\
\text { after the solution is } \\
\text { trialled }\end{array}$ & $\begin{array}{l}\text { An } \\
\text { expert } \\
\text { group: } \\
\sim=5\end{array}$ \\
\hline $\begin{array}{l}\text { On-line } \\
\text { Survey }\end{array}$ & $\begin{array}{l}\text { Clinicians work in } \\
\text { allergy care. } \\
\text { This will be conducted } \\
\text { after the completion of } \\
\text { the focus group. }\end{array}$ & $\begin{array}{l}\text { An } \\
\text { expert } \\
\text { group: } \\
\sim=5\end{array}$ \\
\hline
\end{tabular}

care providers represented the cornerstone in this study.

Both qualitative and quantitative data will be collected from three different sources:

1. Initial discussions with the head of a Melbournian allergy clinic to specify the initial design requirements based on the standard allergy care protocol.

2. Randomly selected de-identified existing patients' records from this clinic to help establish the main structure of the proposed system.

3. A focus group with up to 5 clinicians from this clinic to have their insights on the use of the proposed system, recommendations, and comments on and about the prototype once it is developed.

For data triangulation, an online survey to clinicians will be designed and administrated using SurveyGizmo.

Table 2. A Summary of Data Collection Plan and Techniques

\subsection{Data Collection Plan and Techniques}

Initial discussions have been conducted with the head of the allergy clinic. Through these discussions we have established that the need for an electronic knowledge base with intelligent analysis tools and techniques plus the mobile App is urgently required. Patients' records will be randomly selected with full compliance with ethical requirements. This data is then used to populate the developed knowledge base. The focus group will target up to 5 clinicians who work for the selected clinic. They are recruited based on their daily interaction with patients and their records. Those who participate in the focus group will be requested to complete a follow up survey for data triangulation. Patients who visit the clinic during the 3 month trial period will be asked if they wish to participate in the study (again subscribing to all ethical requirements), and if so, will then be randomly selected into the respective arms of the two arm trial (as described above). All patients will receive equal care and attention irrespective of their participation or not in the study.

Data will be collected using the methods of 1)

De-identified patient records, 2) focus groups, and 3) an online survey (using SurveyGizmo). All patient data will be handled using standard Australian Privacy Principles; including using double de-identified data to ensure confidentiality and anonymity. In addition, all patient data collected will be disclosed only with participants' permission, except as required by law. All information will be stored securely at the study site in a locked office in a filing cabinet and /or password protected computer. Table 2 summarises data collection plan and techniques.

\section{Results to Date and Discussion}

Currently, the initial prototype has been designed (figure 3). This includes design of the backbone knowledge base, and the web portal, and testing them both by using a dummy data set. The initial results show that the knowledge base is robust and capable to be the back-bone supporting system. The next step is to use real de-identified data to test its scalability in real time. The majority of design requirements were met during the design, plus subscribing to the DSRM approach. This will be further confirmed during the second phase of the study. 


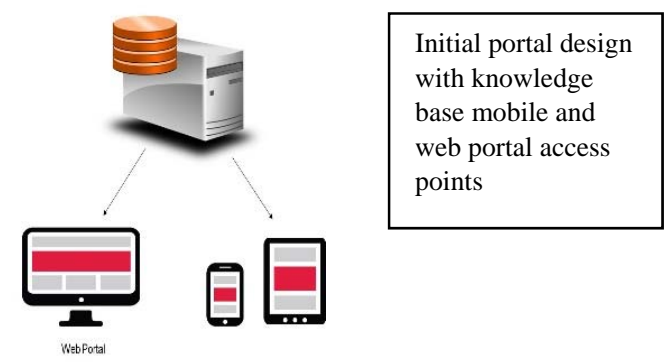

Figure 3 Initial prototype

This research has a number of implications for both theory and practice. From theoretical perspective, this research addresses an urgent need to address the inter-organisational knowledge flow and the potential role of an online system in this regard, specifically in a healthcare context. In addition, it extends the application of the tools and techniques of $\mathrm{KM}$ in the healthcare context. Specifically (figure 4), the knowledge transformation in the knowledge spiral have been addressed. In particular, the knowledge in the knowledge communities (who have the knowledge of the various allergies and allergens and how they respectively must be treated) is now stored systematically and succinctly in the electronic knowledge base, while the harvesting of the relevant information and pertinent knowledge on a case by case basis to assist specific individuals will be done via the mobile app and/or web portal, in addition ne knowledge will be added to the existing extant knowledge base to support the continuous learning cycles.

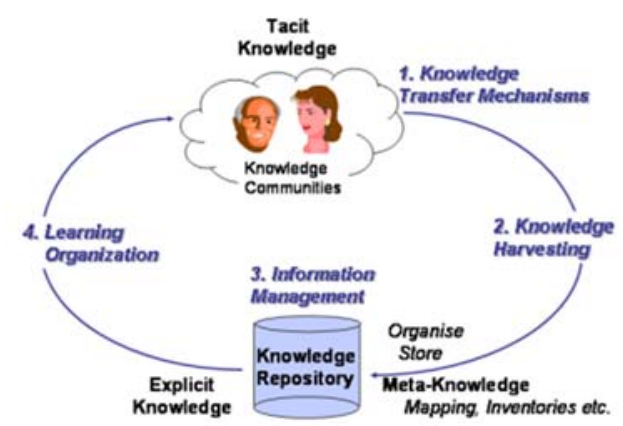

Figure 4. Transformations in the knowledge spiral (adapted from [33])

It also aims at highlighting the technical challenges that may affect the use of such systems and limit their usability. In addition, a further theoretical aspect is the application of DSRM in a healthcare context.

From the perspective of practice we highlight several key aspects as follows: First, the proposed solution is an attempt to address the three problems facing the current model of allergy care; namely, the lack of awareness of allergy care requirements (by enabling educational contents for allergy patients), difficulty accessing specialised allergy care (by increasing the efficiency of care delivery through the use of information technology), as well as the nature of allergy care and the need for higher coordination among different care providers. Secondly, this solution has a potential to enhance the long term follow up of patients attending for comprehensive food allergy management at healthcare contexts. Thirdly, this project has great potential to be patented and commercialised again bringing kudos and financial benefits to healthcare contexts. Fourthly, the outputs of this study are far reaching to patients and their communities in developed countries, particularly in Australia, where allergy rates are among the highest in the world. It is expected that there will be instant and long-term clinical benefits by facilitating proactive and protective allergy care and management practices. The next step of this research is to examine the usability and fidelity of the proposed system at the selected case. The outputs of this testing will be used to further enhance different design and functionality aspects of the proposed system and complete the rigor cycle of the DSRM approach.

\section{Conclusion}

The paper has served to outline a research in progress study that serves to address a healthcare need drawing upon the tools, techniques, and tactics of knowledge management. Specifically, a knowledge-based online solution is designed and developed (figure 3) using a DSRM to address current key issues in the delivery of care for patients suffering from allergies. The developed prototype now is to be tested to establish usability, fidelity, and patient-centeredness. In this way, the impact of the proffered system as a decision support tool powered by integrating key aspects of the tools, techniques, and technologies of knowledge management to enable superior value-based care delivery will be identified and realised. Further, the study highlights the enabling role of technology solutions in the context of allergy care and supporting high value high quality on going care that is patient-centred. In this way it becomes possible to realise the critical role to be played by collaborative technologies in healthcare context. Finally, one are to be addressed relates to the financial aspect. As noted at the start of this paper, the current approaches for treating, managing and monitoring allergy care especially paediatric allergy care is expensive and increasing exponentially. The developed prototype has the potential to minimise waste and provide a high value high quality solution. Currently, it is only possible to 
outline area where waste minimisation and cost containment can take place. Once the final prototype is operational it will also be possible to perform an econometric analysis to identify specific areas of cost savings and thus the true financial implication for allergy care.

\section{Acknowledgement}

The input from Dr Joann Smart is acknowledged with thanks.

\section{References}

[1] AAAAI. ALLERGY STATISTICS. Retrieved May 10, 2016, from http://www.aaaai.org/aboutaaaai/newsroom/allergy-statistics

[2] E.G. Abels, K.W. Cogdill, and L. Zach, L. "Identifying and communicating the contributions of library and information services in hospitals and academic health sciences centers" Journal of the Medical Library Association, 2004, 90(3), 46-55.

[3] Access Economics Pty Limited. The economic impact of allergic disease in Australia: not to be sneezed at. Australia: Australasian Society of Clinical Immunology and Allergy (ASCIA) 2007.

[4] M. Alavi, and D. Leidner, "Review: Knowledge Management And Knowledge Management Systems: Conceptual Foundations And Research Issues". MIS Quarterly, 2001,25(1): 107-136.

[5]Australian Institute of Health and Welfare. Visiting medical officer, 2005, Vol. 327170.

[6] M.C. Bell, and W.W. Busse, "Severe asthma: an expanding and mounting clinical challenge" The Journal of Allergy and Clinical Immunology: In Practice, 2013, 1(2), 110-121.

[7] I. Benbasat, D.K.Goldstein, and M. Mead, "The Case Research Strategy in Studies of Information Systems" MIS Quarterly, 1987, 11(3), 369-386.

[8] T. Davenport, and V. Grover, "Knowledge Management" Journal of Management Information Systems, 2001, vol 18 no.1 pp.3-4

[9] P. Drucker, "Beyond the Information Revolution” The Atlantic Monthly, 1999, Oct pp. 47-57.

[10] A. Dwivedi, and R.K. Bali, A. E. James, and R. N. G. Naguib, "Telehealth Systems: Considering Knowledge Management and ICT Issues," in Proc. IEEE EMBC-2001 23rd Annual International Conference of the IEEE Engineering in Medicine and Biology Society (EMBS), Istanbul, Turkey, 2001, pp. 3614-3617.

[11] J. Duncavage, and D.D. Hagaman," Practical aspects of integrating allergy and pulmonology management into a rhinology practice: the Vanderbilt ASAP experience"
Current opinion in otolaryngology \& head and neck surgery, 2013, 21(1), 74-78.

[12] S. Gregor, and A.R. Hevner, "Positioning and Presenting Design Science Research for Maximum Impact" MIS Quarterly, 2013, 37(2), 337-355.

[13] HealthDirect 2018 (accessed 28 April)

2018.https://www.healthdirect.gov.au/allergy-testing

[14] A.R. Hevner, "A three cycle view of design science research" Scandinavian journal of information systems, 2007, 19(2), 4.

[15] D.J. Hill, R.G.Heine, and C.S. Hosking, "The diagnostic value of skin prick testing in children with food allergy" Pediatric Allergy and Immunology, 2004, 15(5), 435-441. doi: 10.1111/j.1399-3038.2004.00188.x

[16] C. Ho-Chang, E.K. Chang, and V.R. Prybutok, "Information Technology Capability And Firm Performance: Contradictory Findings And Their Possible Causes" MIS Quarterly, 2014, 38(1), 305-A314.

[17] S.W. Hung, and M.J. Cheng, "Are you ready for knowledge sharing? An empirical study of virtual communities" Computers \& Education, 2013, 62, 8-17. doi: http://dx.doi.org/10.1016/j.compedu.2012.09.017

[18] Institute of Medicine, Building a Better Delivery System: A New Engineering/ Health Care Partnership. Washington, D.C.: Institute of Medicine, 2015.

[19] R.B. Johnson, "Examining the validity structure of qualitative research" Education, 1977, 118(2), 282.

[20] I. Muhammad, S. Teoh, and N. Wickramasinghe, "The need for a socio-technical analysis in E-health: The case of the PCEHR" International Journal of E-Health and Medical Communications (IJEHMC), 2013, 4(2), 6579. doi:10.4018/jehmc.2013040105.

[21] I. Nonaka, "A dynamic theory of organizational knowledge creation” Organizational Science, 1994 5: 1437.

[22] Nonaka, I., and Nishiguchi, T. Knowledge Emergence. Oxford University Press, Oxford, 2001.

[23] Nonaka, I., and Takeuchi, N. The Knowledge Creating Company, Oxford University Press, Oxford, 1995.

[24] R. Osborn, D. Moulds, D. Squires, M. Doty, and C. Anderson, "International survey of older adults finds shortcomings in access, coordination, and patientcentered care" Health Affairs (Project Hope), 2014a, 33(12), 2247. doi: 10.1377/hlthaff.2014.0947

[25] R. Osborn, D. Moulds, D. Squires, M. Doty,and C. Anderson, "International Survey Of Older Adults Finds Shortcomings In Access, Coordination, And PatientCentered Care" Health Affairs, 2014b, 33(12), 22472255. doi: http://dx.doi.org/10.1377/hlthaff.2014.0947 
[26] N.J. Osborne, J.J. Koplin, P.E., Martin, L.C. Gurrin, A.J. Lowe, M.C.Matheson, .. . and K.J. Allen,

"Prevalence of challenge-proven IgE-mediated food allergy using population-based sampling and predetermined challenge criteria in infants" The Journal of Allergy and Clinical Immunology, 2011, 127(3), 668676.e662. doi: 10.1016/j.jaci.2011.01.039

[27] K. Peffers, T. Tuunanen, M.A, Rothenberger, and S. Chatterjee, "A design science research methodology for information systems research" Journal of Management Information Systems, 2002, 24(3), 45-77.

[28] R.L.Peters, L.C.Gurrin, S.C.., Dharmage, J.J. Koplin, J. J., and K.J. Allen, "The Natural History of IgE-Mediated Food Allergy: Can Skin Prick Tests and Serum-Specific IgE Predict the Resolution of Food Allergy?" International Journal of Environmental Research and Public Health, 2013, 10(10), 5039-5061. doi: 10.3390/ijerph10105039

[29] Picker Institute, Eye on Patients: A Report by the Picker Institute for the American Hospital Association. Boston, Mass: Picker Institute. 2000.

[30] H.A. Sampson, "Improving in-vitro tests for the diagnosis of food hypersensitivity" Curr Opin Allergy Clin Immunol, 2002, 2(3), 257-261.

[31] R.H. von Alan, S.T. March, J. Park, J., and S. Ram, "Design science in information systems research" MIS Quarterly, 2004, 28(1), 75-105.

[32] N. Wickramasinghe, "Knowledge Creation: A metaFramework” International J. Innovation and Learning 2006 3(5), pp.558-573.

[33] N. Wickramasinghe. "Fostering knowledge assets in healthcare with the KMI model", International Journal of Management and Enterprise Development, 2006 4(1), pp.52-65.

[34] Wickramasinghe, N. and D. von Lubitz, Knowledge-Based Enterprises: Fundamentals and Theories, Idea Group Hershey, 2006.

[35] Wickramasinghe, N., Bali, R., Lehany, B. and Gibbons, C., Schaffer, J. Healthcare Knowledge Management Primer (Routledge Series in Information Systems), ISBN-13: 978-0415994446. Routledge, New Jersey, 2009.

[36] Yin, R.K. Case study research : design and methods (3rd ed. ed.). Thousand Oaks, Calif.: Sage Publications 2003. 